\title{
A Blind-Spot Argument Against Dispositionalist Accounts of Belief
}

\author{
Davide Fassio
}

Received: 14 July 2012 / Accepted: 30 May 2013 / Published online: 13 August 2013

(C) Springer Science+Business Media Dordrecht 2013

\begin{abstract}
Dispositionalist accounts of belief define beliefs in terms of specific sets of dispositions. In this article, I provide a blind-spot argument against these accounts. The core idea of the argument is that beliefs having the form [ $\mathrm{p}$ and it is not manifestly believed that $\mathrm{p}$ ] cannot be manifestly believed. This means that one cannot manifest such beliefs in one's assertions, conscious thoughts, actions, behaviours, or any other type of activity. However, if beliefs are sets of dispositions, they must be manifestable in some way. Therefore, according to my argument, beliefs are not sets of dispositions. The argument is defended against some possible objections.
\end{abstract}

Keywords Belief - Dispositions · Dispositionalist accounts of belief - Blind-spot argument

\section{The Argument}

Dispositionalist accounts of belief define beliefs in terms of specific sets of dispositions. They hold that for someone to believe some proposition $p$ is for that person to possess one or more particular behavioral dispositions pertaining to $p$; for example, dispositions to assert that $p$ in specific situations, to act as if $p$ were true, to consciously entertain the thought that $p$ when deliberating about whether $p$, and so on. Different dispositional accounts are distinguished by the different sets of dispositions considered relevant for belief ascriptions. ${ }^{1}$

\footnotetext{
${ }^{1}$ Dispositionalists are, for example, Braithwaite 1932; Ryle 1949; Marcus 1990 and Schwitzgebel 2002. Here I'm not concerned with any specific kind of dispositionalism. I'm disposed to include under the label 'dispositionalism' views like those of Dennett 1987 and Davidson 1984 (commonly defined as interpretationist) and certain functionalist views like those of Ramsey 1931 and Stalnaker 1984. If sound, my argument is a problem for all those views which require some sort of manifestability of beliefs (what hereinafter I call the Manifestability Condition).
}

D. Fassio $(\bowtie)$

Department of Philosophy, University of Geneva, 2 Rue de Candolle CH-1211, Geneva, Switzerland e-mail: davidefassio@gmail.com 
My aim in this article is to give an argument against dispositional accounts of belief. The argument has a blind-spot structure, like other arguments in philosophical logic such as Moore's and Fitch's paradoxes. ${ }^{2}$ It proceeds as follows. Take a system of modal propositional logic (S5). Add to the language two propositional operators, B and $\mathrm{M}$, standing respectively for 'it is believed that' and 'it is manifestly believed that' ${ }^{3}$ An example of a manifested belief would be a belief manifested by means of a sincere assertion of what is actually believed. Manifestly believing entails believing $(\mathrm{M} \phi \rightarrow \mathrm{B} \phi)$. I assume beliefs and manifested beliefs to hold at least three properties. First, I assume that both the operators distribute over conjunction. In particular, I assume distributivity for $\mathrm{M}$ :

$$
(\operatorname{DistM}) \mathrm{M}(\phi \& \psi) \rightarrow \mathrm{M} \phi \& \mathrm{M} \psi
$$

If it is manifestly believed that ( $p$ and $q$ ), then it is manifestly believed that $p$, and it is manifestly believed that $q \cdot{ }^{4}$ Second, I assume the validity of the following principle:

$$
(\mathrm{I}) \mathrm{M} \neg \mathrm{M} \phi \rightarrow \neg \mathrm{M} \phi
$$

If it is manifestly believed that it is not manifestly believed that $p$, then it is not manifestly believed that $p$. An instance of $\mathrm{M} \neg \mathrm{M} \phi$ is, for example, the belief, manifested by a sincere assertion, that I do not believe that $p .{ }^{5}$ By asserting that I do not believe that $p$, I manifest my belief that I do not believe that $p$. Given that manifested belief entails belief, by modus tollens, if one does not believe that $p$, then one also does not manifestly believe that $p$. So, by asserting that I do not believe that $p$, I'm also manifesting my belief that I do not manifestly believe that $p .^{6}$

The argument is based on two assumptions. A first assumption is a claim on which all dispositionalists agree, namely:

(MC) every belief is manifestable

Let me call this the Manifestability Condition (MC). The validity of this condition for dispositionalism stems from the fact that such accounts aim at a definition of

\footnotetext{
${ }^{2}$ On blind-spot arguments, see Sorensen 1988. For the two quoted paradoxes, see Moore 1942, p. 543 and Fitch 1963.

${ }^{3}$ Operators B and $\mathrm{M}$ are implicitly indexed to specific subjects and times ( $\mathrm{read} \mathrm{B} p$ as "subject $\mathrm{S}$ at some time $t$ believes that $p$ "). I assume that operators in the same formula refer to the same subject, as is common practice in standard doxastic and epistemic logics.

${ }^{4}$ Notice that the distributivity of B is not a necessary assumption for my argument. Distributivity of B has been criticised on the ground that in standard modal logic, it implies single-premise closure (if one believes that $p$ and that $p$ implies $q$, then one believes $q$ ). This is a pretty strong claim: it seems that one can believe both that $p$ and that $p$ implies $q$, but not be able to draw the conclusion that $q$, simply because one is not consciously and explicitly considering the two beliefs. I consider distributivity of $\mathrm{M}$ much more plausible, because it seems more intuitive to consider an actually manifested belief (for example a belief manifested through a sincere assertion) as explicitly and consciously considered.

${ }^{5}$ Sincere assertion is a way of manifesting beliefs. In the present article, I assume that it is the paradigmatic manifestation of belief. On the view that considers sincere assertion as one of the main expressions of belief there is a large body of literature. A famous example is Williams (1970).

${ }^{6}$ (I) is a weaker version of axiom (4) or of axiom (T) in modal logics. The equivalent principle for belief $(\mathrm{B} \neg \mathrm{B} \phi \rightarrow \neg \mathrm{B} \phi)$ is commonly accepted in doxastic logic (see, for example, Hintikka 1962 and Linsky 2009). If it is valid for beliefs in general, it is straightforwardly valid for manifested beliefs. In the second part of the paper I will answer a possible objection against the validity of such a principle.
} 
belief in terms of behavioral dispositions (dispositions to assert, judge, act, behave, and so on), and a necessary feature of dispositions is their possible manifestation given the realization of specific conditions. Consequently, a thing that is not in any way manifestable cannot be a disposition, and thus, according to the characterization of belief given by dispositionalism, would not be a belief at all. ${ }^{7}$ (MC) can be formalised as follows:

$$
(\mathrm{MC}) \mathrm{B} \phi \rightarrow \diamond \mathrm{M} \phi
$$

If it is believed that $\phi$, then it is possible to manifestly believe that $\phi$.

A further plausible assumption is that one may believe some proposition $\mathrm{p}$ and that one is not manifesting such a belief in any way (not sincerely asserting it, not considering it, not acting as if it were true rather than false, and so on). ${ }^{8}$ In such a case one would also believe both these propositions in conjunction ( $p$ and it's not manifestly believed that $p$ ). Consider the following example. Jane believes that her car is yellow. Her belief is not actually manifested in any way. She is actually walking in the street, thinking of things completely unrelated to the color of her car. At the same time she believes that she does not manifestly believe her belief that the car is yellow. She plausibly believes, even if not manifestly, that she is not asserting that her car is yellow, that she is not acting as if her car were yellow rather than not, that she is not consciously judging that the car is yellow, and so on. ${ }^{9}$ Therefore, Jane believes that her car is yellow and that she does not manifestly believe that her car is yellow. Take a particular exemplification of a belief having this logical form. In formal language:

$$
\left(\mathrm{B}^{*}\right) \mathrm{B}(p \& \neg \mathrm{M} p)
$$

It is believed that $[p$ and it is not manifestly believed that $p]$. The argument continues as follows:

$$
\text { 1) } \mathrm{B}(p \& \neg \mathrm{M} p) \rightarrow \diamond \mathrm{M}(p \& \neg \mathrm{M} p) \quad \text { by }(\mathrm{MC}) \text { and }\left(\mathrm{B}^{*}\right)^{10}
$$

\footnotetext{
${ }^{7}$ Notice that this assumption does not amount to the claim that dispositions can be fully analysed in terms of their manifestability conditions. Rather, it amounts to the more modest claim that dispositions are such that, at least in some (normal or ideal) conditions, they can be manifested in some way or another. For this reason, even if the arguments advanced against classical conditional analyses of dispositions - such as, for example, those of Smith 1977 and Johnston 1992 - were valid, they would not be problematic for assumption (MC). Such an assumption does not rely on any conditional account of dispositions. Notice then that so-called finkish dispositions also - dispositions whose conditions for an object's acquiring or losing disposition $D$ are the same as $D$ 's stimulus conditions - are such that they can be manifested in some possible situation in which interfering conditions are not the case. On finkish dispositions see, for example, Martin 1994.

${ }^{8}$ Some philosophers call non-manifested beliefs 'tacit beliefs'. Notice that it is an intuitive matter that we are disposed to ascribe beliefs to people even when they do not manifest them. De facto, it is plausible that, at a given time, the greater part of our beliefs is not actually manifested in speech acts, or behaviours, or in any other way. Notice that dispositionalists have a specific reason for accepting the claim that there are tacit beliefs; one of the motivations for the adoption of a dispositionalist account of belief is precisely the fact that they can make room for the existence of tacit beliefs, which on different accounts (for example linguistic accounts) are not considered genuine beliefs or beliefs at all. See, for example, Marcus 1990, pp. 137-143, and Engel 1999, p. 212.

${ }^{9}$ In the text above I have listed some of the ways in which dispositionalists traditionally think that beliefs can be manifested. Notice, however, that my account can be generalized to any type of belief manifestation, and thus it is potentially effective against more sophisticated dispositionalist accounts of belief.

${ }^{10}$ Substituting $\left(\mathrm{B}^{*}\right)$ for variable $\phi$ in $(\mathrm{MC})$.
} 
2) $\diamond \mathrm{M}(p \& \neg \mathrm{M} p)$

3) $\diamond(\mathrm{M} p \& \mathrm{M} \neg \mathrm{M} p)$

4) $\diamond(\mathrm{M} p \& \neg \mathrm{M} p)$ by ( $\left.\mathrm{B}^{*}\right)$ and (1), Modus Ponens

by (2) and (DistM)

by (3) and (I)

Given the two assumptions $(\mathrm{MC})$ and $\left(\mathrm{B}^{*}\right)$ and the adoption of other plausible properties of beliefs, it follows that a contradiction is possible. But contradictions are impossible. Then one must deny one of the assumptions. Either we deny $\left(\mathrm{B}^{*}\right)$ and accept the implausible claim that, for any proposition $p$, it is necessarily false that it is believed that $p$ and that the belief that $p$ is not manifested, or we deny (MC), the thesis that every belief is manifestable. But, according to dispositionalists, (MC) is a fundamental condition of belief. Denying (MC) entails denying dispositionalism. Whichever of the two assumptions is denied, there is a problem for dispositionalism. ${ }^{11}$

Two remarks are in order here. The first one concerns assumption ( $\left.\mathrm{B}^{*}\right)$. In my view, a weaker assumption can work as well as $\left(\mathrm{B}^{*}\right)$ in deriving the conclusion of the argument. For the argument being generated it does not seem necessary that one hold a belief having precisely the form [ $p$ and does not manifestly believe that $p]$. It seems sufficient that one hold beliefs in propositions having slightly different forms. Consider, for example, the belief that $[p$ and one is not performing a set of activities A], where activities $\mathrm{A}$ are necessary for manifesting the belief that $p$. This belief is not manifestable. In fact, the manifestability conditions of the two conjuncts in the believed content are jointly incompatible insofar as the manifestation of the second conjunct entails that the first conjunct is not manifested. For example, assuming (per absurdum) that the belief that one's car is yellow can be manifested only by asserting its content, Jane's belief that [her car is yellow and she is not asserting anything] would be an instance of unmanifestable belief; for if she coherently manifests that she is not asserting anything (for example, by writing this on a paper, pointing a finger to her closed lips, and so on), she does not assert anything. Consequently, she cannot manifest the first conjunct of the belief (which, by assumption, is manifestable only with an assertion). ${ }^{12,13}$

My second remark is that at least some of the assumptions I made above - in particular concerning assumption $\left(\mathrm{B}^{*}\right)$ - rely on potentially controversial ways of approaching belief ascriptions. For example, even if accepted by several philosophers, the claim that complex propositions of the form considered above can form the content of a single belief

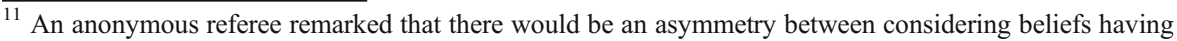
the form of $\left(\mathrm{B}^{*}\right)$ in the first and in the third person, and that a consideration of such cases in the first rather than the third person would be more in the spirit of blind-spot discussions. I disagree with this point. While it is true that one of the main blindspot arguments, Moore's Paradox, relies on first-person belief ascriptions, the majority of blind-spot arguments do not rely on any specific personal perspective and do not differ if stated from a first-person or a third-person perspective. This is also the case for the present argument, which is in many respects very similar to arguments such as Fitch's Paradox of Knowability.

${ }^{12}$ The same point can be made by saying that a stronger version of (I) seems to be valid and could be used to generate a stronger version of the argument: $\left(I^{*}\right)(\mathrm{M} \neg \mathrm{A} \&(p \rightarrow \mathrm{A}) \rightarrow \neg \mathrm{M} p$. Take, for example, the belief, manifested by some action, that I am not asserting anything. Asserting the particular proposition $p$ implies asserting something. Then, according to $\left(I^{*}\right)$, manifesting my belief that I do not assert anything implies that I do not manifestly believe that I am asserting $\mathrm{p}$. The validity of ( $\left.\mathrm{I}^{*}\right)$ entails that propositions having the form $p \& \neg \mathrm{A}$ such that $p \rightarrow \mathrm{A}$ are not manifestly believable. (I*)'s validity seems to be conditional on some minimal coherency constraints of the subject; more on this point will be said in the reply to the first objection in the next section.

${ }^{13}$ Notice also that the mere possible existence of beliefs of this type is sufficient to pose a problem for dispositionalism. In fact, that a possible belief is not manifestable would suffice to provide a counterexample to the claim that beliefs are dispositions, thereby invalidating dispositionalism.
} 
is not uncontroversial, especially if we assume, as some philosophers do, that all beliefs necessarily can have de dicto manifestations. The truth or falsity of this claim relies on difficult unsolved questions about what counts as possession and attribution conditions of belief, on which there may be reasonable disagreement. None of the views about such issues I am aware of is uncontroversial, nor can any be adequately defended in the reduced space of a single paper. Therefore, in my argument, I inevitably have to take some not-uncontroversial positions on these issues. Although I do not pretend to solve all these deep issues here, I will try to address some potential concerns in the next section, where I will provide a partial defence of some of my assumptions.

\section{Possible Objections and Replies}

In this section I consider and address some possible objections to the argument. A first possible objection is the following: dispositionalists could argue that it is too strong to argue that the properties attributed to beliefs and manifested beliefs are universally valid. This is true in particular for principle (I). It has been argued that the principle is valid only in contexts in which the believer is rational. Thus, in the argument, the step from (3) to (4) can be reached only if the believer is rational. The contradictory conclusion follows only if rational constraints are met by the believer. In other words, the conclusion can be turned from the derivation of an inconsistency to the derivation of an inconsistency in situations of theoretical rationality. However, in my view, this is a sufficiently bad consequence for dispositionalists. It would amount to the claim that it is not rationally believable that one can hold beliefs involving the logical form of $\left(\mathrm{B}^{*}\right)$. Furthermore, as I said in note 6, many philosophers are disposed to endorse the validity of principle (I). (I) follows from other very plausible properties of beliefs. In particular, one can derive (I) from other principles admitted in doxastic logic: from principle $\mathrm{M} \phi \rightarrow \neg \mathrm{B} \neg \mathrm{M} \phi$ or from the two following principles $\mathrm{M} \phi \rightarrow \mathrm{BM} \phi$ and $\mathrm{B} \phi \rightarrow \neg \mathrm{B} \neg \phi$.

Other possible objections may be addressed to the assumption that there are beliefs having the logical form exemplified by $\left(\mathrm{B}^{*}\right)$, according to which someone believes that $p$ and that she does not manifestly believe that $p$. A first possible objection is the following: a belief can be manifested by means of different types of activities, for instance, by consciously judging that $p$, asserting that $p$, acting as if $p$, and so on. It may be that for some of the activities in which we are not engaged, we have tacit beliefs to the effect that we are not engaged in them; nevertheless - the objection goes - it is implausible that, for each activity allowing the manifestation of a certain belief in which one is not at the time engaging, one has a tacit belief to the effect that one is not engaging in that activity. This assumption would have the consequence of overpopulating the mind by attributing as many tacit beliefs as would be needed to cover every possible belief-manifesting activity in which one is not at the time engaged.

I have two possible answers to this objection. First, it is plausible that for some beliefs there is a limited range of possible manifestations. This is the case, for example, for beliefs whose conceptual complexity is such that they can be manifested only by judging or asserting their content, or for beliefs whose content cannot be expressed with language, such as beliefs about specific feelings, manifestable only by consciously considering them with an act of introspection. Now, assume that a belief that $p$ can be manifested by one single type of activity A. It is plausible that one can believe that she is 
not engaging in the only activity that could manifest the belief that $p$. Similarly, it is also plausible that one can believe this proposition in conjunction with $p$. My second reply to this objection is that, as argued above, to hold a belief having the logical form of $\left(\mathrm{B}^{*}\right)$, it is not necessary that, for each activity manifesting the relevant belief, said activity is believed not to be performed. Rather, it would be sufficient to hold the generic belief that $p$ and that no activity manifesting the belief that $p$ is actually being performed. ${ }^{14}$

The distinction between tacit beliefs and dispositions to believe, first suggested by Audi (1994), is the basis for a second possible concern one might have regarding the validity of the assumption that there are beliefs taking the logical form of $\left(\mathrm{B}^{*}\right) .{ }^{15} \mathrm{~A}$ tacit belief is one that is not occurrently believed, but is accessible by a retrieval process that draws on memory, while a disposition to believe is a mere potentiality of forming a new belief through belief-formation processes. ${ }^{16}$ Consider the following example: even if one answers affirmatively to the question whether she believes that 235 is a larger number than 59, until one consciously considers the proposition and occurrently believes it, one does not antecedently believe it. In this case, one has only a disposition to believe this proposition; this disposition is manifested only when one explicitly considers whether 235 is larger than 59. The very act of considering this proposition causes the formation of that belief, which was not antecedently held. On the contrary, tacit beliefs are antecedently held and recalled to memory when consciously considered. For example, a tacit belief might be one that is acquired in certain perceptual ways without thinking of the propositions thereby believed, such as the unconscious belief that it is raining outside formed by looking out the window without paying attention to the fact that it is raining. ${ }^{17}$ When a tacit belief is reflectively considered, one doesn't form a new belief, but, rather, simply recalls the pre-existing belief from her memory. On the basis of this distinction, one could object to my assumption that beliefs having the logical form of $\left(\mathrm{B}^{*}\right)$ are not tacit beliefs but only mere dispositions to believe. Such attitudes would not be beliefs; thus their unmanifestability would not constitute a case against dispositionalist accounts of belief. ${ }^{18}$

I am not convinced by Audi's distinction between tacit beliefs and dispositions to believe. While I don't deny Audi's distinction at a phenomenological level, it is unclear to me whether instances of what Audi calls 'dispositions to believe' must be regarded as

\footnotetext{
${ }^{14}$ It is possible that there are a very few or no beliefs having the logical form of $\left(\mathrm{B}^{*}\right)$. However, I think that it is reasonable to assume at least that we can hold some tacit beliefs that take this form. Yet, even the mere possibility of a belief having or entailing this form is sufficiently problematic for dispositionalist accounts of belief, providing a potential instance of unmanifestable belief. Likewise, notice that, as mentioned in the first remark at the end of the first section, in order for this argument to be effective, it is not necessary that one form the belief that she does not manifestly believe that $p$ in particular. It is sufficient to believe that one is not performing the generic type of activities that allow the manifestation of the belief that $p$.

${ }^{15}$ Audi also refers to tacit beliefs as 'dispositional beliefs'.

16 See Audi 1994, pp. 419-421.

${ }^{17}$ An example of tacit belief offered by Audi is the following: "While absorbed in conversation, one might come to believe, through hearing a distinctive siren, that an ambulance went by, but without thinking of this proposition or considering the matter" (ibid., p. 421).

${ }_{18}$ Similarly, notice that, given a similar blind-spot argument, a disposition to believe a proposition having the form $[p$ and it is not manifestly believed that $p]$ would be unmanifestable, and therefore problematic. One could, however, argue that there are no such dispositions to believe, precisely because such dispositions are dispositions to occurrently believe some proposition, but we cannot occurrently believe propositions having the considered form. What we would be disposed to believe would be each conjunct in the conjunction, $p$ and that it is not manifestly believed that $p$.
} 
mere potentialities to believe rather than genuine antecedently held beliefs. After all, as Audi observes, ordinary intuitions about belief attributions confirm that we regard these as antecedently held beliefs. We are disposed to ascribe to ourselves the belief that 235 is larger than 59; and to do so not only from the moment in which we consciously realize its truth, but also at a time preceding any conscious consideration of this proposition as well. ${ }^{19}$ A different account, able to preserve both the explanatory advantages of the distinction and the linguistic intuitions confirming the genuine doxastic nature of socalled 'dispositions to believe' would be preferable. ${ }^{20}$ However, if what Audi identifies as mere dispositions to believe are actually beliefs, then according to dispositionalism such beliefs must also be manifestable, neutralizing the considered objection. In fact, even if beliefs having the logical form of $\left(\mathrm{B}^{*}\right)$ were not tacit beliefs in the narrow sense used by Audi, they would still be beliefs held antecedently to any conscious consideration, and therefore constrained by manifestability conditions. This, in turn, would engender the blind-spot argument proposed herein.

Nevertheless, even granting the validity of Audi's distinction, there are grounds for arguing that beliefs having the logical form of $\left(\mathrm{B}^{*}\right)$ are tacit beliefs rather than mere dispositions to believe. This is confirmed by a test used by Audi to distinguish the two types of attitude: tacit beliefs are beliefs stored in one's memory and recalled when they become occurrent; on the contrary, dispositions to believe are dispositions to form beliefs not yet held in the memory, thus not remembered by the agent forming them. As Audi observes (Ibid., p. 420), one who is merely disposed to believe a given proposition cannot be said to remember, or for that matter, to have forgotten the proposition, or even to have this proposition preserved in his memory. It seems wrong for one to say that one remembers that 235 is larger than 59 when one considers this belief for the first time. In contrast, it makes perfect sense to say that one remembers what is tacitly believed, as when one says that she remembers that yesterday it wasn't raining, even if she never thought of this proposition or considered the matter. Similarly, one may remember that she wasn't engaging in certain activities required for the manifestation of a belief. For example, one may recall that yesterday it was raining, and she didn't say a word about the fact that it was raining, didn't act as if it were raining,

\footnotetext{
${ }^{19}$ Intuitively, one believes that 235 is larger than 59 even before she reflectively considers that proposition. The intuition that one knew that proposition before such a reflective consideration is even stronger. But, if knowledge entails belief, then one also believed the proposition before any reflective consideration.

${ }^{20}$ Audi refers to this possible interpretation as assimilationism (Ibid., p. 430). He describes this view as distinguishing two ways of dispositionally believing; one which Audi calls "retentional," taking dispositional beliefs as stored in the memory and available for presuppositions in assertion and action, and the other "affirmational," according to which whatever we sincerely tend to affirm when questioned is sincerely believed. The main reason adduced by Audi against this view is that, if all dispositions to believe are actually beliefs, they must be stored somewhere in the mind, which would overpopulate our minds with too many beliefs. In my view, however, the view defended by Audi is affected by the opposite problem, that it seems to posit far fewer beliefs than what we have, at least according to ordinary belief ascriptions. Furthermore, the problem of mind overpopulation has been traditionally considered a problem specific to views assuming a non-modal, spatial existence of beliefs, such as representationalism, according to which beliefs would be representations registered in a spatially limited memory. An advantage traditionally attributed to non-representational accounts of belief - such as dispositionalism and pure functionalism over representationalism is precisely that the former views can easily account for the actual possession of a potentially infinite number of beliefs. In fact, at least in principle, there are no limits to the dispositions a thing may possess, since dispositions are modal properties, mere potentialities of action and behavior which do not occupy a limited physical space.
} 
and so on. ${ }^{21}$ According to the memory test, beliefs which are, at least partially, about the absence of performance of certain activities - such as those having the form of $\left(\mathrm{B}^{*}\right)$ can be classified as tacit beliefs, and not as mere dispositions to believe. ${ }^{22,23}$

Another possible concern regarding the assumption that there are beliefs that take the logical form exemplified by $\left(\mathrm{B}^{*}\right)$ is that it is not uncontroversial that any set of true claims can form the content of a single belief. It can be argued that one cannot hold single beliefs that possess conjunctions as content - in general, or in the specific case of beliefs having the form of $\left(\mathrm{B}^{*}\right)$. In this perspective, believing a conjunction would merely consist of holding two single beliefs in each conjunct. This would be problematic for my argument: if it were true, the beliefs in each conjunct in $\left(\mathrm{B}^{*}\right)$ would not be jointly manifestable, yet they could be individually manifested. Therefore this argument is only effective assuming that it is possible to have single beliefs that have the logical form of $\left(\mathrm{B}^{*}\right)$.

Assuming that complex propositions (e.g., conjunctions) can be the content of single beliefs, it seems plausible that any pair of propositions $p$ and $q$ believed singularly, are also believed in conjunction. ${ }^{24}$ If Jane believes that it is raining in Paris and believes that it is

\footnotetext{
${ }^{21}$ In order to clarify the nature of beliefs having the logical form of $\left(\mathrm{B}^{*}\right)$, it is useful to further consider the analogy between perceptual tacit beliefs and beliefs about the absence of performance of certain activities. Some philosophers have recently argued that tacit perceptual beliefs do not bear only on the perception of the presence of things, but also on the perception of their absence. See, for example, Soteriou 2011. So, for example, one could come to believe that it isn't raining by perceiving that it isn't. Such a perceptuallyformed belief seems to be in all respects a tacit belief; in fact, it passes Audi's tests for tacit beliefs, such as the memory test and the presupposition availability test (see footnote 23). A way in which one can conceive of (at least some) beliefs which are about the absence of the performance of some activity, such as those having the form $\left(\mathrm{B}^{*}\right)$, is as sorts of perceptual beliefs partially formed on the basis of one's unconscious introspective perception of the absence of one's agential performance. Consider the following example: yesterday I could have introspectively perceived that I didn't say that it was raining or acted as if it were, even if I saw that it was; I could have thereby formed a tacit belief on the matter based on this inner perception, and now recall this belief from memory.

${ }^{22}$ Of course, if a held belief has the logical form of ( $\left.\mathrm{B}^{*}\right)$, it cannot pass the memory test, for such belief is unmanifestable and thus, one cannot remember it. However, beliefs having a similar structure, but such that the doxastic operators are indexed at a past time (such as the exemplified S's belief that yesterday it was raining and S didn't manifest that belief), may be remembered, and thus may pass the test. Beliefs with the logical form $\left(\mathrm{B}^{*}\right)$ are in all respects similar to the exemplified one, except that the second conjunct is not indexed at a past time, but rather, at every time. On the implicit time index of the doxastic operators in the argument, see footnote 3 .

${ }^{23}$ Another test used by Audi for distinguishing between tacit beliefs and dispositions to believe seems to confirm that beliefs that we are not performing, or have not performed, certain activities, are tacit beliefs. According to Audi (Ibid., pp. 424-425) what is (tacitly or occurrently) believed is presuppositionally available in thought and discourse; for example, as a premise for inference or as spontaneously assertible in talking about topics on which the proposition in question bears. On the contrary, what one is merely disposed to believe is only indirectly available, say, through considering the proposition or placing it in the light of one's background beliefs. Now, in ordinary life, we often presuppose in our assertions and actions beliefs about activities that we didn't perform. For example, if Mary says something to John with the intention of informing him about this thing, her assertion presupposes that she didn't say it to him before of course, assuming also that Mary respects the conversational maxim of quantity, requiring one not to be more informative than necessary. From this it follows that Mary tacitly believed that thing.

${ }^{24}$ Notice that, for any $p$ and $q, \mathrm{~B} p \& \mathrm{~B} q \rightarrow \mathrm{B}(p \& q)$ is a theorem of standard doxastic logics. One may object that, if for every couple of beliefs in basic propositions there is a belief in the conjunction of these propositions, then subjects have an infinite number of beliefs. However, as stated in footnote 20, the problem of beliefs' overpopulation of the mind has been traditionally considered a problem specific to views assuming a non-modal, spatial existence of beliefs, such as representationalism. The potential infinity of one's beliefs supports views such as dispositionalism and pure functionalism, which can easily account for the actual possession of a potentially infinite number of beliefs.
} 
sunny in London, she also believes that it is raining in Paris and it is sunny in London. The same is valid for propositions involved in beliefs having the form of $\left(\mathrm{B}^{*}\right)$ : if Mary believes that it is raining in Paris and believes that she doesn't manifestly believe that it is raining in Paris, it is plausible that she also believes that it is raining in Paris and she does not manifestly believe that it is raining in Paris - i.e., 'it is raining in Paris and I do not manifestly believe that it is raining in Paris' can be the content of a single belief that Mary has. Therefore, given the assumption that complex propositions can be the content of single beliefs, I don't see any principled reason for denying that some of these may be instantiations of the logical form $\left(\mathrm{B}^{*}\right) .^{25}$

However, the claim that complex propositions can be the content of single beliefs i.e., that beliefs do not have as content only basic propositions - is not uncontroversial. It can be argued that, in general, beliefs whose content is apparently constituted by complex propositions are just sets of beliefs about basic propositions. I cannot provide here an adequate defense that complex propositions can be the content of single beliefs. ${ }^{26}$ I will assume this claim here. However, I will briefly suggest some reasons in support of it.

Intuitions about belief attributions show that we are disposed to attribute single beliefs having conjunctions as content. For example, it is perfectly appropriate to say that Mary's belief that Beijing is the capital of China and that its population is over ten million is correct. Similarly, it is important to note that often the superficial syntactical form of belief ascriptions does not help to ascertain whether a belief possesses as content a complex proposition or not. In some cases it is extremely difficult to draw a neat distinction between basic and complex propositions. This makes any reduction of beliefs whose content is apparently constituted by complex propositions to beliefs about basic propositions even more challenging. Consider the following case: Joe believes that he truly believes that Tom is happy and that today is Saturday. In such a case, it is unclear how many basic propositions Joe believes. Some examples of possible answers include: i) one belief whose content is captured by the sentence following the first "that" clause in the sentence; ii) two beliefs with content that Joe truly believes that Tom is happy, and that Joe truly believes that today is Saturday; iii) the two beliefs mentioned in (ii) plus the belief that Joe's beliefs are true; and iv) the two beliefs mentioned in (ii) plus the two beliefs that each of them is true. ${ }^{27}$ Certainly,

\footnotetext{
${ }^{25}$ As said, I don't see any principled reason for denying such a claim. The dispositionalist may argue that a reason for denying the existence of beliefs having the form of $\left(\mathrm{B}^{*}\right)$ is precisely the fact that such beliefs face the blind-spot problem. However, this move would be completely ad hoc, not based on any independent principled reason for thinking that there are no such beliefs except the aim to escape a specific objection to their view. The dispositionalist must provide an independent reason for denying the validity of the principle $\mathrm{B} p \& \mathrm{~B} q \rightarrow \mathrm{B}(p \& q)$ for these (and only for these) propositions. Otherwise her rejection of this principle only for propositions that could generate a problem for her view seems blatantly ad hoc.

${ }^{26}$ Different accounts of the content of propositional attitudes are available, some compatible with this claim, while others are not. At one extreme there are views according to which only basic propositions can be the content of beliefs, and complex beliefs are agglomerates of beliefs about basic propositions. At another extreme, there is the view according to which we actually hold one unique hyper-complex belief representing all the states of affairs one takes to be true. In order to defend the claim that single beliefs about complex propositions are possible, I should criticize a number of accounts incompatible with this claim; unfortunately, this is a task that cannot be accomplished in this paper.

${ }^{27}$ Similar considerations are valid for beliefs generating the blind-spot problem, which do not need to be explicitly stated in terms of beliefs about conjunctions. Consider the belief that I'm not manifesting my actually held belief that it is raining. This is apparently not a belief in a conjunction - at least at a superficial syntactical level. However, as is the case for beliefs explicitly having the form of $\left(\mathrm{B}^{*}\right)$, this belief is not coherently manifestable.
} 
intuitions about belief attributions and the difficulty of drawing a neat distinction between basic and complex propositions do not provide definitive arguments that complex propositions can be the content of single beliefs; however, they do provide at least some clue in support of this claim. ${ }^{28}$

\section{Conclusion}

In this article, I provided an argument against dispositional accounts of belief. The core idea of the argument consists in showing that there are beliefs that cannot be manifestly believed (i.e., beliefs that cannot be manifested in assertion, conscious thought, action, behavior, or any other type of activity). The existence of this type of belief conflicts with a central tenet of dispositionalists, namely that insofar as beliefs are dispositions, they must be manifestable in some way. I then defended my argument against some possible objections.

Surely this argument must not be regarded as a definitive refutation of dispositionalist accounts of beliefs - for one thing because, as pointed out above, it partially relies on some not uncontroversial assumptions about belief ascriptions and the nature of belief. Endorsing controversial assumptions seems inevitable, after all, in domains in which every presupposition has been the object of very deep disputes in the literature. However, the argument still constitutes a problem, both for philosophers accepting my assumptions and presuppositions and for those who want to argue for the validity of doxastic dispositionalism without being forced to take any specific stand on what the appropriate conditions of belief possession and attribution are. For these philosophers, the argument can constitute an interesting challenge and can motivate them to provide not ad-hoc solutions to it. A careful consideration of the threat posed by the argument could bring dispositionalists to refine their positions, leading to further advancements in this field of research. In this perspective, the argument can also be seen as a useful stimulus motivating further elaborations and developments of dispositionalist theories of belief, which may eventually help to reorient the future research on the topic.

Acknowledgments I am particularly grateful to Julien Dutant, Pascal Engel, and an anonymous referee of this journal for extensive discussions of the ideas in this article. I would like to thank the members of the Episteme research group of the University of Geneva for their helpful comments, and the Swiss National Science Foundation for financial support.

\section{References}

Armstrong, D. M. (1973). Belief, truth, and knowledge. London: Cambridge University Press.

Audi, R. (1994). Dispositional beliefs and dispositions to believe. Noûs, 28(4), 419-434.

Braithwaite, R. B. (1932). The nature of believing. Proceedings of the Aristotelian Society, 33, 129-146.

Davidson, D. (1984). Inquiries into truth and interpretation. Oxford: Clarendon.

Dennett, D. C. (1987). The intentional stance. Cambridge: MIT.

\footnotetext{
${ }^{28}$ Another well known problem for the view that beliefs' contents include only basic propositions is constituted by beliefs about existential and universal propositions. Propositions of this type are not reducible to beliefs about basic propositions. See, for example, Armstrong 1973, Ch. 6 and 7.
} 
Engel, P. (1999). Dispositional beliefs, assent, and acceptance. Dialectica, 53, 211-226.

Fitch, F. (1963). A logical analysis of some value concepts. Journal of Symbolic Logic, 28(2), $135-142$.

Hintikka, J. (1962). Knowledge and belief: An introduction to the logic of the two notions. Ithaca: Cornell University Press.

Johnston, M. (1992). How to speak of the colors. Philosophical Studies, 68, 221-263.

Linsky, B. (2009). Logical types in arguments about knowability and belief. In J. Salerno (Ed.), New essays on the knowability paradox (pp. 163-182). Oxford: Oxford University Press.

Marcus, R. B. (1990). Some revisionary proposals about belief and believing. Philosophy and Phenomenological Research, 50, 132-153.

Martin, C. B. (1994). Dispositions and conditionals. The Philosophical Quarterly, 44, 1-8.

Moore, G. E. (1942). In P. A. Schlipp (Ed.), A reply to my critics. The philosophy of G. E. Moore. Evanston: Northwestern University.

Ramsey, F. P. (1931). The foundations of mathematics, and other logical essays. London: Routledge \& Kegan Paul.

Ryle, G. (1949). The concept of mind. New York: Barnes \& Noble.

Schwitzgebel, E. (2002). A phenomenal, dispositional account of belief. Nous, 36, 249-275.

Smith, A. D. (1977). Dispositional properties. Mind, 86, 439-445.

Sorensen, R. A. (1988). Blindspots. Oxford: Clarendon Press.

Soteriou, M. (2011). The perception of absence, space, and time. In J. Roessler, H. Lerman, \& N. Eilan (Eds.), Perception, causation, and objectivity. Consciousness and self-consiousness. Oxford: Oxford University Press.

Stalnaker, R. (1984). Inquiry. Cambridge: MIT.

Williams, B. (1970). Deciding to believe. In H. E. Kiefer \& M. K. Munitz (Eds.), Language, belief, and metaphysics (pp. 95-111). Albany: SUNY Press. Reprinted in Williams, B. (1973). Problems of the Self. London: Cambridge University Press, pp. 136-151. 